\title{
Canadian hereditary angioedema guideline
}

Stephen Betschel ${ }^{1 *}$, Jacquie Badiou ${ }^{2}$, Karen Binkley $^{1}$, Jacques Hébert ${ }^{3}$, Amin Kanani $^{4}$, Paul Keith ${ }^{5}$, Gina Lacuesta ${ }^{6}$, Bill Yang ${ }^{7}$, Emel Aygören-Pürsün ${ }^{8}$, Jonathan Bernstein ${ }^{9}$, Konrad Bork $^{10}$, Teresa Caballero ${ }^{11}$, Marco Cicardi ${ }^{12}$, Timothy Craig ${ }^{13}$, Henriette Farkas ${ }^{14}$, Hilary Longhurst ${ }^{15}$, Bruce Zuraw ${ }^{16}$, Henrik Boysen ${ }^{17}$, Rozita Borici-Mazi ${ }^{18}$, Tom Bowen ${ }^{19}$, Karen Dallas ${ }^{20}$, John Dean ${ }^{21}$, Kelly Lang-Robertson ${ }^{1}$, Benoît Laramée ${ }^{22}$, Eric Leith ${ }^{23}$, Sean Mace , Christine McCusker ${ }^{24}$, Bill Moote ${ }^{25}$, Man-Chiu Poon ${ }^{26}$, Bruce Ritchie ${ }^{27}$, Donald Stark ${ }^{4}$, Gordon Sussman ${ }^{1}$ and Susan Waserman ${ }^{5}$

\begin{abstract}
Hereditary angioedema (HAE) is a disease which is associated with random and often unpredictable attacks of painful swelling typically affecting the extremities, bowel mucosa, genitals, face and upper airway. Attacks are associated with significant functional impairment, decreased Health Related Quality of Life, and mortality in the case of laryngeal attacks. Caring for patients with HAE can be challenging due to the complexity of this disease. The care of patients with HAE in Canada is neither optimal nor uniform across the country. It lags behind other countries where there are more organized models for HAE management, and where additional therapeutic options are licensed and available for use. The objective of this guideline is to provide graded recommendations for the management of patients in Canada with HAE. This includes the treatment of attacks, short-term prophylaxis, long-term prophylaxis, and recommendations for self-administration, individualized therapy, quality of life, and comprehensive care. It is anticipated that by providing this guideline to caregivers, policy makers, patients and their advocates, that there will be an improved understanding of the current recommendations regarding management of HAE and the factors that need to be considered when choosing therapies and treatment plans for individual patients. The primary target users of this guideline are healthcare providers who are managing patients with HAE. Other healthcare providers who may use this guideline are emergency physicians, gastroenterologists, dentists and otolaryngologists, who will encounter patients with HAE and need to be aware of this condition. Hospital administrators, insurers and policy makers may also find this guideline helpful.
\end{abstract}

Keywords: Hereditary angioedema, Guideline, Recommendations, Acute attacks, Short-term prophylaxis, Long-term prophylaxis, Self-administration, Individualized therapy, Quality of life, Comprehensive care, GRADE

\footnotetext{
* Correspondence: betschels@smh.ca

'University of Toronto, Toronto, Ontario, Canada

Full list of author information is available at the end of the article
} 


\section{Introduction \\ Background}

Hereditary angioedema due to $\mathrm{C} 1$ inhibitor deficiency (C1-INH-HAE) is an autosomal dominant condition with an estimated prevalence of approximately 1:50,000 [1,2]. It results in random and often unpredictable attacks of painful swelling typically affecting the extremities, bowel mucosa, genitals, face and upper airway [3]. Attacks are associated with significant functional impairment, decreased Health Related Quality of Life (HRQoL), and mortality in the case of laryngeal attacks $[4,5]$. The swelling in HAE is a result of impaired regulation of bradykinin synthesis [6]. Bradykinin is a nonapeptide kinin formed from high molecular weight kininogen by the action of plasma kallikrein. Bradykinin is a very powerful vasodilator and increases capillary permeability, constricts smooth muscle and stimulates pain receptors [1].

HAE can be categorized into 3 different types depending on the level and function of C1inhibitor (C1-INH): type 1(HAE-1), type 2 (HAE-2), and HAE with normal C1-INH function (HAE-nC1INH) previously referred to as type 3 (Table 1). HAE-1 is the most prevalent, representing approximately $85 \%$ of cases and results from low antigenic and functional levels of C1-INH. HAE-2 accounts for approximately $15 \%$ of cases and is associated with a normal C1-INHprotein level but impaired C1INH function $[7,8]$. C4 is reduced in $98 \%$ of cases for both HAE-1 and HAE-2, and nearly $100 \%$ of the time during an attack [7].

HAE-nC1INH (previously referred to as type 3 HAE), is much less prevalent than HAE-1 and HAE-2. The true prevalence is not known as there are no reliable assays to screen for this condition. In about $20 \%$ to $25 \%$ of identified patients, causative mutations in the gene coding for the coagulation factor XII ( $F 12)$ have been found (HAE-nC1INHFXII) whereas in the remaining patients no genetic cause has been identified up to now (HAE-nC1INH-unknown) [11-13]. The exact pathogenesis, however, including the mode of action of the $F 12$ gene mutations and the role of estrogens is still unknown. The lack of laboratory and genetic assays (with the exception of $F 12$ gene mutations) to diagnose HAE-nC1INH, has made the identification of these patients more difficult than patients with HAE-1 or HAE-2. A recent international consensus group has

Table 1 Laboratory findings in hereditary angioedema

\begin{tabular}{lccc}
\hline & C4 & C1-INHAntigen & C1INH Function \\
\hline HAE - 1 & $\downarrow$ & $\downarrow$ & $\downarrow$ \\
HAE - 2 & $\downarrow$ & Normal or & $\uparrow$ \\
HAE - nC1INH & & & $\downarrow$ \\
- FXII mutation & Normal & Normal & Normal \\
-UnknownCause & Normal & Normal & Normal \\
\hline
\end{tabular}

References $[9,10]$. published criteria to make the diagnosis of HAE-nC1INH [13]. These included a history of recurrent angioedema in the absence of concomitant hives or use of medication known to cause angioedema; documented normal or near normal C4, C1-INH antigen and function; and either a F12gene mutation associated with the disease, or family history of angioedema and documented lack of efficacy of chronic high dose non-sedating antihistamine therapy [13].

Management of HAE can be divided into various approaches. The aim of treatment of acute attacks, also referred to as 'on demand therapy' is to minimize their severity, including potentially fatal upper airway edema, and associated impairment of Quality of Life (QoL). Short term prophylaxis (STP) refers to treatment meant to minimize the risk of attacks when avoidance of potential and known triggers is not possible. Long term prophylaxis (LTP) refers to ongoing treatment of HAE aimed at minimizing the overall number, frequency and/or severity of attacks. The details of specific therapies for these treatment approaches will be discussed in the sections that follow. In addition to the evidence behind the proposed recommendations, the clinical considerations for their implementation will also be discussed. The United States Preventive Services Task Force describes clinical considerations as statements that can help clinicians by offering practical information so they can tailor guideline recommendations to individual patients [14]. This Clinical Consideration section following each recommendation is intended to help place the recommendation into a clinical context.

\section{Scope and purpose}

The objective of this guideline is to provide graded recommendations for the management of patients in Canada with HAE-1, HAE-2 and HAE-nC1INH. This includes the treatment of attacks, STP, LTP, and recommendations for self-administration, individualized therapy, QoL, and comprehensive care.

The care of patients with HAE in Canada is neither optimal nor uniform across the country. It lags behind other countries where there are more organized models for HAE management, and where additional therapeutic options are licensed and available for use [15]. It is anticipated that by providing this guideline to caregivers, policy makers, patients and their advocates, that there will be an improved understanding of the current recommendations regarding management of HAE and the factors that need to be considered when choosing therapies and treatment plans for individual patients.

It is not the intent of this guideline to provide a detailed description of the pathophysiology or nomenclature of HAE which can be found elsewhere [13]. It is also not intended to be prescriptive in its recommendations, but rather to highlight issues that need to be considered when 
choosing treatments options for patients with a focus on the importance of individualized care.

\section{Intended audience}

The primary target users of this guideline are healthcare providers who are managing patients with HAE-1, HAE-2 and HAE-nC1INH. Other healthcare providers who may use this guideline are emergency physicians, gastroenterologists, dentists and otolaryngologists, who will encounter patients with HAE and need to be aware of this condition. Hospital administrators, insurers and policy makers may also find this guideline helpful.

\section{Methods}

\section{Committee members and consensus conference participants}

The Canadian Hereditary Angioedema Guideline Committee is a working committee under the umbrella of the Canadian Hereditary Angioedema Network (CHAEN)/ Réseau Canadien d'angioédème héréditaire (RCAH) http:// chaen-rcah.ca/. Members on this committee included members from CHAEN/RCAH across Canada as well as the President of the Canadian HAE Patient Organization Hereditary Angioedema (HAE) Canada/Angioédème Héréditaire (AEH) Canada. The Canadian Hereditary Angioedema Committee was responsible for defining the scope and purpose of the guideline and choosing the international participants. International participants were selected based on their contributions to the HAE literature, relating to HAE and its management, and their expertise in priority areas for this guideline including self-administration, individualized therapy, HRQoL, and comprehensive care. Those identified experts were asked to present a summary of the evidence related to these areas to all conference participants.

Conference participants included the CHAEN/RCAH Guideline Committee, international experts, all currently registered members of CHAEN who were able to attend the meeting, the President of HAE/AEH Canada and their designates, President of the international HAE patient group HAEi, Hema-Quebec, and industry representatives. An invitation was extended to representatives of the Provincial/Territorial Blood Coordinating offices.

Representatives from Industry, who manufacture products for the treatment of $\mathrm{HAE}$, were also invited to provide information on their products if required during the meeting. Only medical personnel and general managers were invited but were not present during times when decisions were made. Marketing representatives were excluded.

\section{Funding and support}

Funding for the CHAEN/RCAH Guideline Conference was done through the CHAEN/RCAH. This organization received equal support from 3 companies, who manufacture products for the treatment of hereditary angioedema (CSL Behring, Shire, and ViroPharma - Viropharma was acquired by Shire between the time of the guideline meeting and publication of the Guideline). Requests to procure funding from Provincial and National Government and Blood Agencies were not successful. Funding was used to support rental of the conference facilities, audio-taping, facilitation by an external facilitator, travel to the meeting, accommodation, and foods for all participants except for government agency representatives and patient representatives who were supported by their own agencies. No industry participants were funded by CHAEN/RCAH. No participants at the meeting were compensated for their time except for the Guideline meeting methodologist and facilitator from the Centre of Effective Practice.

The guideline meeting process was aided by a methodologist and a guideline facilitator from the Centre for Effective Practice and supported by HAE/AEH Canada.

\section{Conflict of interest}

Details of potential conflicts of interest were elicited using the standardized International Committee of Medical Journal Editors Form for Disclosure of Potential Conflicts of Interest (Additional file 1). COI forms were distributed to attendees prior to their reviewing the manuscript, and were mandatory for all contributing authors.

\section{Identifying the evidence}

A systematic search of Ovid MEDLINE was conducted by a librarian from the Centre for Effective Practice (KLR) on October 10, 2013, in order to identify clinical trials addressing long-and short-term prophylaxis and treatment of acute attacks in patients of any age diagnosed with HAE-1, HAE-2, or HAE-nC1INH. Outcomes of interest included frequency or severity of attacks, symptom relief and QoL measures as reported or measured by the affected subject or investigator. Studies were limited to English language publications, and there were no limits on the publication date of study other than those imposed by the database (1946October week 1, 2013). After duplicates were removed, 416 results were found, the abstracts of which were reviewed to determine if they met the inclusion criteria. If unclear from the abstract whether the paper met these criteria, the full-text document was reviewed. One hundred and thirty two results were retrieved and reviewed in full text, and from this, 11 relevant randomized control trials and 34 lower-quality comparative studies without blinding or randomization were identified and included. No studies which met the inclusion criteria were identified for HAE-nC1INH. The full search strategy is available in Additional file 2. 


\section{Summarizing and evaluating the evidence}

Key information from the included studies such as study design, number of patients, outcome measures, side effects and funding source was extracted into evidence tables for each intervention (see Additional file 3). Evidence tables were provided to the Committee Members and were available for reference at the meeting.

Criteria for determining Levels of Evidence and Strength of Recommendation were adapted from the GRADE system, [16-18] and the process was based primarily on the Journal of Clinical Epidemiology's 2011-2013 series of articles describing the GRADE methodology. GRADE is considered "outcome centric," and traditionally recommends a single rating for each outcome across the full body of evidence. The method applied here involved evaluating the quality of each study individually, and then looking at the studies together to assign a Level of Evidence based on the collection of studies.

Each identified randomized control trial was assessed by two reviewers (KL-R, VP) for quality using the Cochrane Risk of Bias Tool [19]. Any disagreements were resolved by a third reviewer (SB). Randomized trials were initially rated as High quality levels of evidence, with quality being downgraded for evidence of bias on the Cochrane tool and if there was evidence of inconsistency (Additional file 3: Table S1). Non-randomized, non-blinded trials were considered to be Low quality evidence.

Multiple factors were considered when assigning the Strength of Recommendation, including quality of evidence, balance between desirable and undesirable effects, values and preferences, and costs (Additional file 3: Table S2).

Additional file 3 describes additional detail how quality was assessed and the criteria used to determine the Strength of Recommendation. The quality ratings were presented at the meeting during the discussion of draft recommendations. Additional files 4 and 5 list the HAE RCT evidence tables and the lower quality comparison study evidence respectively.

\section{Recommendation development and approval}

The Chair (SB) developed draft recommendations based on the identified literature, and presented them to the Committee Members who approved them in draft. Invited Committee Members were assigned specific topic areas and were asked to review the evidence relevant to their topic and present the body of evidence for consideration at the Guideline meeting. After the summary was presented, the Consensus Conference Participants were provided an opportunity to discuss the literature. Following this discussion, the draft recommendation was presented and the group discussed the specific wording of the recommendation before voting anonymously via electronic voting to agree or disagree with the recommendation, or abstain. If $80 \%$ consensus was not reached, there was additional group discussion, the recommendation was rephrased, and a new vote conducted. This process was conducted a maximum of 3 times. If $80 \%$ consensus was not reached, it was considered that the committee was unable to reach consensus.

Once the phrasing of a recommendation was approved by the group, the proposed Level of Evidence was presented by the methodologist guideline facilitator (High, Moderate, Low, Very Low, or Consensus). The Level of Evidence was then discussed, revised if necessary, and similarly voted on as outlined above.

The suggested Strength of Recommendation (Strong or Weak) was then presented to the group. The methodologist guideline facilitator proposed a Strength of Recommendation based on the Level of Evidence, the balance between desirable and undesirable effects, values and preferences. These factors were discussed amongst the group before voting to accept the proposed Strength of Recommendation. All votes were recorded and presented in real time with the recommendations. Table 2 is a summary of all the recommendations, the level of evidence supporting each recommendation, and the strength of each recommendation.

For each topic area, group discussions were captured on audiotape, and used to inform the clinical considerations for each recommendation.

To mitigate any real or perceived bias that may have influenced the outcomes, industry representatives at the meeting were asked to leave the room after the scientific presentations and were not present during any discussion either of the data, wording of the recommendations, levels of evidence, strength of recommendations, or the voting process.

Prior to the in-person meeting, the Committee Members determined that open discussion amongst conference participants regarding an approach to individualized therapy would be beneficial. For this topic, small round table discussions were facilitated prior to recommendation review and voting, and additional clinical considerations were.

\section{Guideline recommendations}

Treatment of acute attacks of HAE types 1 and 2

\section{Background}

Acute attacks of HAE may be spontaneous or precipitated by an external stimulus and range from mild to life-threatening. The decision to treat an attack depends on many variables and the severity of an attack cannot always be predicted by its earliest manifestations. The aim of treating acute attacks is to reduce the duration and severity of an attack, to minimize the impact of an attack on the functional ability of the patient, and reduce morbidity and potential mortality.

Despite the increase in available beneficial therapies, some therapies which have not been shown to be effective in trials continue to be used in acute attacks due to either historical precedent or lack of awareness. 


\section{Treatment of Acute Angioedema Attacks}

1. Effective therapy should be used to treat acute attacks of angioedema to reduce duration and severity of attacks.

2. pdC1-INH is an effective therapy for the treatment of acute attacks.

3. Icatibant is an effective therapy for the treatment of acute attacks.

4. Ecallantide is an effective therapy for the treatment of acute attacks.

5. rhC1-INH is an effective therapy for the treatment of acute attacks.

6. Attenuated androgens should not be used to treat acute attacks.

7. Tranexamic acid should not be used to treat acute attacks.

8. Frozen plasma could be used for treatment of acute attacks if other recommended therapies are not available.

9. We recommend early treatment of attacks to reduce morbidity (Level of Evidence: Moderate) and mortality (Level of Evidence: Expert Opinion).

10. All attacks of angioedema involving the upper airway are medical emergencies and must be treated immediately. (Level of Evidence: Low) In addition, we recommend emergency department assessment. (Level of Evidence: Expert Opinion).

\section{Acute Treatment of HAE with Normal C1-INH}

11. There is insufficient evidence to make a recommendation for or against the use of HAE-specific therapies in the treatment of acute attacks in patients with HAE with normal C1-INH.

\section{Short-Term Prophylaxis}

12. Short-term prophylaxis should be considered prior to known patient-specific triggers and for any medical, surgical or dental procedures.

13. HAE-specific acute treatment should be available during and after any procedure.

\section{Long-Term Prophylaxis In HAE 1 \& 2}

14. Long-term prophylaxis may be appropriate for some patients to reduce frequency, duration and severity of attacks.

15. Attenuated androgens are effective for long-term prophylaxis in some patients.

16. Plasma-derived C1-INH is effective for long-term prophylaxis in some patients.

17. Anti-fibrinolytics are effective for long-term prophylaxis in some patients.

18. It is not necessary to fail other long-term prophylaxis therapies before use of $\mathrm{C} 1-\mathrm{INH}$ for long-term prophylaxis is considered.

19. There is insufficient evidence to make a recommendation for or against long-term prophylaxis for patients with HAE with normal C1-INH.

\section{Self-Administration}

20. All patients should be trained on self-administration of HAE-specific therapies if they are suitable candidates. If patients cannot self-administer therapy, provisions should be made to ensure timely access to all appropriate therapies.

\section{Approach to Individualized Therapy}

21. The decision to start or stop long-term prophylaxis depends on multiple factors and should be made by the patient and an HAE specialist.

\section{Quality of Life}

22. Health care providers should specifically address factors known to affect quality of life with HAE patients. Management of HAE should aim to improve patients' quality of life.

\section{Comprehensive Care}

23. Comprehensive care should be available for all patients with HAE.
High, Strong

High, Strong

High, Strong

High, Strong

High, Strong

Low, Strong

Low, Strong

Low, Strong

Moderate, Strong/Expert Opinion, Strong

Low/Expert Opinion, Strong

Very Low / Insufficient Evidence

Low, Strong

Low, Strong

High, Strong

Moderate, Strong

High, Strong

Moderate, Strong

Expert Opinion, Strong

Very Low/Insufficient Evidence

Low, Strong

Expert Opinion, Strong

Low, Strong
Nine randomized trials were identified which demonstrated improvement in duration and severity of acute attacks of HAE types 1 and 2 [20-29]. The therapies studied were plasma derived C1-INH (pdC1-INH), recombinant human $\mathrm{C} 1-\mathrm{INH}$ (rhC1-INH), icatibant and ecallantide. Table 3 lists the specific agents, their 
Table 3 Therapies for HAE supported by high level of evidence

\begin{tabular}{|c|c|c|c|c|c|}
\hline $\begin{array}{l}\text { HAE specific } \\
\text { treatment }\end{array}$ & $\begin{array}{l}\text { Product name and } \\
\text { company }\end{array}$ & $\begin{array}{l}\text { Mechanism of } \\
\text { Action }\end{array}$ & $\begin{array}{l}\text { Approved } \\
\text { Indications In } \\
\text { Canada }\end{array}$ & Dose & Adverse Events \\
\hline \multirow[t]{2}{*}{$\begin{array}{l}\text { C1-INH } \\
\text { - Plasma }\end{array}$} & Berinert $^{\oplus}$ (CSL) & Replaces Cl-INH & $\begin{array}{l}\text { Acute } \\
\text { treatment }\end{array}$ & $20 \mathrm{IU} / \mathrm{Kg}$ intravenous & $\begin{array}{l}\text { Anaphylaxis/Thrombosis (rare); Transmission } \\
\text { of infectious agents (theoretical) }\end{array}$ \\
\hline & Cinryze $^{\oplus}$ (Shire) & Replaces Cl-INH & $\begin{array}{l}\text { Long term } \\
\text { Prophylaxis }\end{array}$ & $\begin{array}{l}1000 \text { IU q3-4 days } \\
\text { intravenous }\end{array}$ & $\begin{array}{l}\text { Anaphylaxis/Thrombosis (rare); Transmission } \\
\text { of infectious agents (theoretical) }\end{array}$ \\
\hline - Recombinant & Rhucin $^{\circledast}$ (Pharming) & Replaces CI-INH & Not licensed & $50 \mathrm{U} / \mathrm{Kg}$ Intravenous & Anaphylaxis (rare) \\
\hline Ecallantide & Kalbitor $^{\circledast}$ (Dyax) & $\begin{array}{l}\text { Inhibits plasma } \\
\text { kallikrein }\end{array}$ & Not licensed & $\begin{array}{l}30 \mathrm{mg} \text { subcutaneous } \\
\text { injection }\end{array}$ & Anaphylaxis (uncommon) \\
\hline \multirow[t]{2}{*}{ Icatibant } & Firazyr ${ }^{\oplus}$ (Shire) & $\begin{array}{l}\text { Blocks bradykinin } 2 \\
\text { receptor }\end{array}$ & $\begin{array}{l}\text { Acute } \\
\text { treatment }\end{array}$ & $\begin{array}{l}30 \mathrm{mg} \text { subcutaneous } \\
\text { injection }\end{array}$ & $\begin{array}{l}\text { Pain, swelling, pruritis at injection site } \\
\text { (common) }\end{array}$ \\
\hline & & & & & $\begin{array}{l}\text { Exacerbation of coronary artery disease } \\
\text { (theoretical) }\end{array}$ \\
\hline
\end{tabular}

mechanism of action, their licensed indications in Canada, the recommended dosages, and important potential adverse reactions. The quality of individual studies is described under the drug-specific recommendations which follow. Based on the rating of each study using the Cochrane Risk of Bias Tool (see Additional file 4), as well as the overall consistent effect of therapy on the relevant outcomes (reduction of duration and severity of acute attacks), and effect size, this body of evidence determined by the conference participants to be of High quality.

Based on the Level of Evidence, the potential severity of the outcomes and the low risk of adverse effects, the panel voted for a Strong Recommendation in favour of the use of effective therapies in the treatment of acute attacks.

\section{Recommendation 1 \\ Effective therapy should be used to treat acute attacks of angioedema to reduce duration and severity of attacks. \\ Level of Evidence: High (96\% Agree, 4\% Disagree) \\ Strength of Recommendation: Strong (100\% Agree)}

\section{Clinical considerations}

The panel emphasized the importance of changing practice towards the use of effective therapies based on evidence based data, and specifically not using therapies which were not supported by evidence, such as antihistamines, corticosteroids and epinephrine which are directed at treating histamine mediated angioedema.

\author{
Recommendation 2 \\ pdC1-INH is an effective therapy for the treatment \\ of acute attacks. \\ Level of Evidence: High (100\% Agree) \\ Strength of Recommendation: Strong (100\% Agree)
}

\section{Clinical considerations}

The pdC1-INH is a human blood product. Treatment with pdC1-INHreplaces the deficient protein in patients with HAE-1 and HAE-2.Berinert ${ }^{\circ}$ (CSL Canada) is the only licensed product in Canada for the treatment of acute attacks of HAE-1 and HAE-2. It has been licensed since 2010, and is available throughout Canada, through Canadian Blood Services or Hema-Quebec. It can be used to treat all attacks of HAE- 1 and HAE-2 in adults and children. The recommended dosage is $20 \mathrm{U} / \mathrm{kg}$ administered intravenously either by healthcare professionals or by patients and their caregivers who have been trained in its administration. It has been shown to effectively treat acute attacks in pediatric and adult patients with HAE-1 and HAE-2 [22].

Although not currently licensed in Canada for the treatment of acute attacks, Cinryze ${ }^{\circledast}$ (Shire) is licensed in Europe for treatment of acute attacks in adolescent and adult patients with HAE-1 and HAE-2at a dose of 1000 units intravenously initially and another 1000 units if no response. It has been shown to reduce the median time to onset of unequivocal relief of symptoms compared to placebo group [29].

The dose derived for treatment of acute attacks comes from clinical trials. There have been no head to head trials comparing products so it cannot be concluded that different doses of different products were equally effective. There is some evidence that efficacy is dose dependant, but this has not been confirmed with rigorous dose finding trials [30]. The pdC1-INH products are safe and well tolerated when used as indicated with no documented transmission of infectious agents.

\section{Recommendation 3}

Icatibant is an effective therapy for the treatment of acute attacks.

Level of Evidence: High (97\% Agree, 3\% Disagree) Strength of Recommendation: Strong (96\% Agree/ 4\% Disagree) 


\section{Clinical considerations}

Bradykinin is a key mediator in inducing angioedema through activation of the bradykinin B2 receptor [6]. Icatibant is a synthetic 10-amino acid peptide and acts as a selective bradykinin B2 receptor antagonist. It is administered as a single $30 \mathrm{mg}$ subcutaneous injection. It has been shown to effectively treat acute attacks in adult patients with HAE-1 and HAE-2 [20,25]. Icatibant is licensed in Europe and the USA for self-administration for the treatment of HAE attacks. (Addendum: Icatibant was licensed by Health Canada July 16, 2014). It is generally welltolerated, although $90 \%$ of patients experience transient local pain, swelling, and erythema at the injection site.

\section{Recommendation 4 \\ Ecallantide is an effective therapy for the treatment of acute attacks. \\ Level of Evidence: High (94\% Agree, 6\% Disagree) \\ Strength of Recommendation: Strong (94\% Agree, 6\% Disagree)}

\section{Clinical considerations}

Plasma kallikrein generates bradykinin through cleavage of high-molecular-weight kininogen [6,31,32]. Ecallantide is a 60 -amino acid recombinant protein that acts as an inhibitor of kallikrein. It is administered as three $10 \mathrm{mg}$ subcutaneous injections for a total dose of $30 \mathrm{mg}$. It has been shown to effectively treat acute attacks in adolescent and adult patients with HAE-1 and HAE-2 [26]. MartinezSaguer et al. [33] ecallantide (is not currently licensed in Canada but access can be requested through) the Special Access Program of Health Canada. Hypersensitivity and sometimes anaphylactic-type reactions have been described with this agent in 5\% or administrations, of which approximately $50 \%$ were possible anaphylactic reactions. Subcutaneous administration is associated with fewer of these episodes (1.6\%), but is still a concern [32]. In the USA, ecallantide is approved for treatment of acute attacks, but must only be administered by healthcare professionals who are trained and are prepared to treat adverse reactions.

\section{Recommendation 5 \\ rhC1-INH is an effective therapy for the treatment of acute attacks. \\ Level of Evidence: High (100\% Agree) \\ Strength of Recommendation: Strong (97\% Agree, $3 \%$ Abstain)}

\section{Clinical considerations}

The rhC1-INH (conestat-alpha) is generated in the mammary glands of transgenic rabbits and is identical to pdC1-INH except for the degree of protein glycosylation [34]. This difference in glycosylation results in shorter plasma mean half-life of the recombinant product $[33,35]$, however the effect this has on physiologic activity is not known [30]. It has been shown to effectively treat acute attacks in adult patients with HAE-1 and HAE-2 [28]. It is administered intravenously at a dose of $50 \mathrm{U} / \mathrm{kg}$ in people up to $84 \mathrm{Kg}$ and at a dose of $4200 \mathrm{U}$ for people above $84 \mathrm{Kg}$. Because of an isolated anaphylactic reaction after administration of rhC1-INH to a rabbit allergic person, those with anti-rabbit IgE should be excluded before prescribing. It is not currently licensed in Canada but access can be requested through the Special Access Program of Health Canada.

\section{Recommendation 6}

Attenuated androgens should not be used to treat acute attacks.

Level of Evidence: Low (97\% Agree, 3\% Abstain)

Strength of Recommendation: Strong (100\% Agree)

\section{Recommendation 7}

Tranexamic acid should not be used to treat acute attacks.

Level of Evidence: Low (93\% Agree, 7\% Disagree)

Strength of Recommendation: Strong (83\% Agree, 10\% Disagree, 7\% Abstain)

\section{Clinical considerations}

Attenuated androgens such as the $17 \alpha$-alkylated anabolic androgen danazol and anti-fibrinolytic drugs such as tranexamic acid have not been shown to be efficacious in the treatment of acute attacks of HAE-1 and HAE-2. Given the lack of evidence for these agents in the acute treatment of HAE, the Committee strongly agreed that they should not be used for the treatment of acute HAE attacks as other agents with documented efficacy are available in Canada.

\section{Recommendation 8}

Frozen plasma could be used for treatment of acute attacks if other recommended therapies are not available.

Level of Evidence: Low (96\% Agree, 4\% Abstain) Strength of Recommendation: Strong (100\% Agree)

\section{Clinical considerations}

Frozen plasma (FP) is a blood product which contains C1INH in association with other plasma proteins. Frozen plasma (FP) is not as safe as solvent detergent plasma (SDP) with respect to pathogen inactivation, and the level of evidence that frozen plasma is effective in the treatment of acute attacks of HAE -1 and HAE-2 is low. It also contains potential substrates for the generation of additional bradykinin and in theory could worsen attacks of angioedema. Also, not all blood banks in Canada stock FP and 
there are special requirements to enable access to SDP. Hence, there may be a significant delay in getting FP and/ or SDP in a timely manner - in some cases up to 24 hours. Therefore, it was strongly felt by the Committee that frozen plasma products, although potentially beneficial, should only be used if other recommended therapies are not available and that every effort should be made to ensure timely and appropriate therapy for acute attacks [36,37].

\section{Recommendation 9}

We recommend early treatment of attacks to reduce morbidity (Level of Evidence: Moderate) and mortality (Level of Evidence: Expert Opinion).

Level of Evidence: Moderate (92\% Agree, 8\% Disagree) Strength of Recommendation: Expert Opinion/

Strong (92\% Agree, 4\% Disagree, 4\% Abstain)

\section{Clinical considerations}

Early treatment likely leads to more rapid symptom resolution. Observational studies have suggested that early treatment can be efficacious in reducing the duration of an attacking some patients [38-42]. Therefore, despite the absence of a high level of evidence, expert opinion was strong endorsing early treatment in an attempt to reduce morbidity and likely mortality. Because of the potential barriers in accessing therapy in a timely manner, patients should be trained on how to self-administer therapies appropriate for the treatment of acute attacks of HAE. If patients are not able to self-administer their own therapy, efforts should be made to ensure that this therapy is made available to them without a significant delay (see Recommendation \#21).

\section{Recommendation 10}

All attacks of angioedema involving the upper airway are medical emergencies and must be treated immediately. (Level of Evidence: Low) In addition, we recommend emergency department assessment. (Level of Evidence: Expert Opinion).

Level of Evidence: Low (96\% Agree, 4\% Disagree) Strength of Recommendation: Expert Opinion/ Strong (100\% Agree)

\section{Clinical considerations}

Attacks of HAE are unpredictable and potentially lifethreatening. Mortality due to laryngeal angioedema is well recognized [3]. All attacks of laryngeal angioedema should be considered medical emergencies, and therapies that have been shown to be effective in the treatment of HAE should be readily available and given immediately. It is also recommended that all patients with laryngeal edema, even following self-therapy, be assessed in the emergency department in the event that the angioedema does not respond to therapy, and expertise in airway management is required [43].
Treatment of acute attacks of HAE with normal C1 INH function

Background

HAE-nC1INH is a rare disease that can be a challenge to diagnose with certainty as was discussed above. It has been suggested, without confirmatory evidence that bradykinin may play a role in the pathogenesis of this disease which has led to speculation that therapies used for HAE-1 and HAE-2 may be beneficial [13]. There is also indirect evidence that anti-histamine therapy is not effective in this patient group [44]. Owing to the difficulty in identifying this subset of patients with HAE, and that there have been neither significant case series nor controlled clinical trials with respect to therapeutic intervention for acute attacks, we cannot recommend specific therapeutic interventions as this time.

\section{Recommendation 11}

There is insufficient evidence to make a recommendation for or against the use of $\mathrm{HAE}$ specific therapies in the treatment of acute attacks in patients with HAE with normal C1-INH. Level of Evidence: Very Low (96\% Agree, 4\% Disagree) Strength of Recommendation: Insufficient Evidence (N/A)

\section{Clinical considerations}

The committee felt that there was insufficient evidence to make a specific recommendation regarding the use of therapies that have been shown to be efficacious for the acute treatment of HAE-1 and HAE-2 in patients with HAE-nC1INH.

However, in spite of this, if patients meet the clinical profile of HAE-nC1INH, a trial of HAE specific therapy could still be considered with the understanding that there is a very low level of evidence to support this and some reports demonstrate lack of efficacy for use of either pdC1INH or icatibant [45-48]. This may not be surprising given that there are neither abnormalities in C1-INH level or function, nor any confirmatory evidence if a role for bradykinin.

\section{Short-term prophylaxis Background}

STP refers to the practice of treating patients to reduce the risk of associated and consequent morbidity and mortality during a period of time when there may be an increased risk of having an attack of angioedema.

It is well recognized that physical trauma, as can occur during medical and dental procedures, can induce episodes of angioedema [49,50]. Upper airway manipulation, including during dental surgery and intubation, is at particularly high risk due to its association with upper airway swelling. However, even minor procedures can precipitate angioedema and the ability to predict when 
this may occur cannot be made with certainty. Attacks can occur anywhere from hours to several days after a procedure [49].

It is also suspected that other causes, such as emotional stressors can precipitate attacks. Individual patients may also be aware of specific triggers that have been known to trigger their attacks.

Despite these observations, there is a lack of controlled clinical trials in this area, and most data come from retrospective reviews and surveys [49,51-53].

\section{Recommendation 12 \\ Short-term prophylaxis should be considered prior to known patient-specific triggers and for any medical, surgical or dental procedures. \\ Level of Evidence: Low(96\% Agree, 4\% Disagree) Strength of Recommendation: Strong (93\% Agree, 7\% Disagree)}

\section{Recommendation 13 \\ HAE-specific acute treatment should be available during and after any procedure. \\ Level of Evidence: Low(92\% Agree, 4\% Disagree, 4\% Abstain) \\ Strength of Recommendation: Strong (100\% Agree)}

\section{Clinical considerations}

There was extensive discussion as to when STP should be used and consideration was given to the development of a list of high and low risk procedures in this context. However, there is lack of data regarding the specific risk associated with each of a wide range of medical and dental procedures; it was felt that STP should be considered for all medical, surgical and dental procedures. One study assessed the risk of angioedema following surgery without prior pre-procedural prophylaxis as $5-30 \%$, irrespective of type and extent of surgery [53]. Based on this, and our inability to link the risk of an attack to a specific procedure $[49,53]$; it was felt that STP should at least be considered for all procedures as well as known patientspecific triggers. This recommendation was intended to remain broad in its scope as the risk of appropriate STP would likely be minimal compared to any real or perceived risk of not using STP when felt necessary. If the decision is made not to administer STP, all patients should have two acute treatment doses of appropriate therapy immediately available as per Recommendation 13. What is not known from the current data is how many patients have been denied, or have chosen not to pursue necessary procedures due to perceived risks, or not being offered STP. Ensuring access to STP may help mitigate the risk associated with procedures and enable patients to seek and receive the care they need [54].
In the absence of rigorous data on specific dosing, pre-procedural prophylaxis with pdC1-INHconcentrate is recommended however there have not been controlled dose finding studies. Response however does appear to be dose related. In one study patients had about a 30\% risk with no prophylaxis, $15 \%$ risk with 500 units of pdC1-INH which was reduced to about 5\% risk at 1000 units [49]. Furthermore, given that breakthrough attacks have occurred even with prophylactic pdC1-INH concentrates at 1,000 units, at least one additional treatment for acute attacks should be available. In Canada, pdC1INHBerinert ${ }^{\circ}$ is approved by Health Canada for acute treatment and pdC1-INH Cinryze is approved by Health Canada for long-term prophylaxis. In Europe, Cinryze is licensed to be given 1000 units within 24 hours of the procedure, or Berinert1000 units within 6 hours of an anticipated procedure.

Attenuated androgens may be considered for STP when surgery-related risk is considered low and other HAEspecific acute treatments are not immediately available. If androgens are chosen for STP, Danazol can be considered starting 5 days before the anticipated procedure or trigger and continuing 2-3 days after the anticipated trigger (Danazol 2.5 to $10 \mathrm{mg} / \mathrm{kg} /$ day, maximum $600 \mathrm{mg} /$ day) [9]. Disadvantages with androgen therapy include perceived inferior efficacy to pdC1-INH concentrate and side effects such as emotional irritation and lability, menstrual disturbance, and vaginal dryness which can occur with short term use. Attenuated androgens areal so not suitable in pregnancy nor during breast feeding, and a pregnancy test should be considered before initiation of therapy with androgens. Recurrent short-term uses may be associated with similar effects seen with long-term androgen use as discussed below.

Anti-fibrinolytic agents such as tranexamic acid have been used for STP with suggested dosages of $25 \mathrm{mg} / \mathrm{kg}$ 2-3 times daily to a maximum of 3-6 g per day, 5 days before and 2-5 days after the procedure or anticipated trigger. The efficacy for prevention of attacks, however, is unknown and this agent should only be used if other therapies are not available.

\section{Long-term prophylaxis in HAE types 1 and 2 Background}

LTP refers to the use of ongoing regular treatment to prevent attacks of HAE when on demand treatment does not sufficiently meet patient treatment requirements as discussed below in the Approach to Individualized Therapy section. Prophylactic therapy may be considered for patients with recurrent episodes of angioedema to reduce the frequency, duration and severity of attacks. The specifics of when to consider and when to initiate LTP are discussed below. 


\section{Recommendation 14 \\ Long-term prophylaxis may be appropriate for some patients to reduce frequency, duration and severity of attacks. \\ Level of Evidence: High (100\% Agree) \\ Strength of Recommendation: Strong (100\%)}

\section{Clinical considerations}

The aim of LTP is to reduce the frequency and/or severity of attacks of HAE and minimize the impact of HAE on their QoL so as to enable patients to live normal lives. Some patients may be candidates for long-term therapy and the benefits and risks associated with such treatments should be explored to optimize patient care. It is important to remember that no prophylactic regimen has been associated with the complete elimination of angioedema. Therefore, despite being on prophylaxis, all patients should be equipped to treat acute attacks in a manner consistent with Recommendation \#1 and an acute treatment plan should be agreed between patient and physician.

\section{Recommendation 15 \\ Attenuated androgens are effective for long-term prophylaxis in some patients. \\ Level of Evidence: Moderate (92\% Agree, 4\% \\ Disagree, 4\% Abstain) \\ Strength of Recommendation: Strong (90\% Agree, 6\% Disagree, 4\% Abstain)}

\section{Clinical considerations}

Controlled trials and observational studies have demonstrated that treatment with 17-alpha-alkylated anabolic androgens, such as danazol, reduces the frequency and severity of HAE attacks [55-60]. Although one of the trials was a randomized controlled trial the level of evidence for the trial was not considered High as there were insufficient details on funding, sequence generation, and outcome reporting [55]. Historically, many patients have been controlled with androgen therapy and their use in some patients may be acceptable provided that the lowest effective dose is used to achieve efficacy and minimize adverse effects. Expert opinion suggests the optimal dose for danazol, to minimize adverse effects, is $\leq 200 \mathrm{mg} /$ day [9].

Androgens can affect serum lipid levels, can be hepatotoxic resulting in hepatitis and have been associated with hepatocellular adenoma and, in very rare cases, carcinoma $[58,61,62]$. It is recommended that all patients on androgen therapy be monitored for hypertension and have a complete blood count, liver enzymes, urinalysis, serum alpha-fetoprotein, creatine phosphokinase and lipid profile performed every 6 months, and an annual liver ultrasound [15].

Virilising effects of androgen therapy can occur and include menstrual irregularities, masculinization, irreversible voice alteration, and hirsutism. Psychological side effects include emotional irritability and lability, aggressive behaviour and depression. Androgens are associated with interactions with several medications. They are contraindicated in pregnancy and during lactation, before puberty, and in patients with androgen-dependent malignancy and hepatitis [61,62].

Patients need to be made aware of these side effects when considering and while on androgen therapy and physicians should carefully consider the risks and benefits for the particular patient.

\section{Recommendation 16 \\ Plasma-derived C1-INH is effective for long-term prophylaxis in some patients. \\ Level of Evidence: High (100\% Agree) \\ Strength of Recommendation: Strong (100\% Agree)}

\section{Clinical considerations}

Controlled clinical trials have demonstrated that pdC1INH used for prophylaxis in HAE-1 and HAE-2 reduces the number, duration and severity of attacks of angioedema $[27,29]$. Currently, Cinryze ${ }^{\oplus}$ (Shire) is the only approved pdC1INH product for HAE prophylaxis in Canada. However, this product has not yet been distributed in Canada. The dose of pdC1INH studied was 1000 $\mathrm{U}$ once or twice weekly (usually every 3-4 days). No dose finding studies have been done and at 1000 units twice a week the attacks are reduced by only $50 \%$.

Side effects reported in trials with pdC1-INH are minimal. In the trial of Cinryze ${ }^{\oplus}$ for LTP, 21 of 24 subjects $(88 \%)$ had one or more adverse events, however only three adverse events (pruritus and rash, light-headedness, and fever) were classified as possibly related to the study drug. Two patients in that study demonstrated an increase in the number of attacks of HAE. A paper based on the FDA registry of drug related adverse events, reported 10 cases of severe thrombosis related to the use of Cinryze ${ }^{\circ}$ in three years between 2008 and 2011 [63]. The reason for these thrombotic events has not been further elucidated. It has been assumed to be related to the use of central lines. However, the use of these should also be avoided due to the associated risk of serious infection $[63,64]$.

On-going monitoring of a patients response to therapy is recommended. In addition, as intravenous therapy requires ongoing venous access follow-up should ensure proper technique is used to maximize the health of the veins.

\section{Recommendation 17}

Anti-fibrinolytics are effective for long-term prophylaxis in some patients.

Level of Evidence: Moderate (96\% Agree, 4\% Disagree)

Strength of Recommendation: Strong (86\% Agree, 14\% Disagree) 


\section{Clinical considerations}

The benefit of the anti-fibrinolytic agent tranexamic acid was demonstrated in a randomized placebo controlled trial with 18 subjects aged 12 years and overtaking $1 \mathrm{~g}$ of tranexamic acid three times a day [65], and a double-blind crossover study of epsilon aminocaproic acid in 9 patients aged 7 to 40 years resulting in these agents being given a moderate level of evidence [66]. These data suggested that anti-fibrinolytic agents could be useful for LTP for HAE-1 and HAE-2. However, their role in current LTP was felt to be justified only in some patient groups due to the lack of efficacy and the potential side effects at the dosage studied. Although not specifically studied in paediatric patients, it was felt, due to the concern of using attenuated androgens in this patient demographic, that anti-fibrinolytic agents could be considered. The recommended dosage for tranexamic acid is $30-50 \mathrm{mg} / \mathrm{kg}$ daily divided in 2 or 3 doses to a maximum of $6 \mathrm{~g}$ per day.

\section{Recommendation 18 \\ It is not necessary to fail other long-term prophylaxis therapies before use of pdC1-INH for long-term prophylaxis is considered. \\ Level of Evidence: Expert Opinion (100\% Agree) \\ Strength of Recommendation: Strong (100\% Agree)}

\section{Clinical considerations}

The elements to consider when deciding to start prophylaxis are discussed below, in the approach to individualized therapy section. However, there is no recommended order or hierarchy for which therapies should be chosen for LTP. This should be based on the efficacy of the therapy, its side effects and safety, and the patient's preference. The participants were unanimous in their recommendation that should a patient require long-term prophylaxis they can be started on prophylactic pdC1-INH without need to be tried on other prophylactic therapies first.

\section{Long-term prophylaxis in HAE with normal C1-INH function Background}

Patients with HAE-nC1INH share similar clinical characteristics with $\mathrm{HAE}-1$ and $\mathrm{HAE}-2$ patients, including the risk of random unpredictable attacks of debilitating and potentially life threatening angioedema [44]. These similarities have led to speculation that treatments used for LTP for HAE-1 and HAE-2 may be beneficial for patients with $\mathrm{HAE}-\mathrm{nC} 1-\mathrm{INH}$; however, due to the lack of data a recommendation for this intervention could not be made.

\section{Recommendation 19}

There is insufficient evidence to make a recommendation for or against long-term prophylaxis for patients with HAE with normal C1-INH. Level of Evidence: Very Low (100\% Agree) Strength of Recommendation: Insufficient Evidence (N/A)

\section{Clinical considerations}

The absence of good evidence in the LTP of HAE with nC1-INHpatients makes it difficult to make specific recommendations regarding treatment. Patients should avoid known triggers of angioedema such as exogenous estrogen and angiotensin converting enzyme (ACE) inhibitors. There is some evidence that progesterone, anti-fibrinolytics and attenuated androgens may be efficacious in patients with HAE-nC1INH [12]. However, the data were of low quality and uniform recommendations could not be made regarding their use. The committee felt strongly that more data are needed in this area and appropriate trials should be done to help guide future treatment recommendations.

\section{Self-administration Background}

Self-administration refers to the treatment of patients outside of a health care facility either by the patient's themselves or by a trained caregiver. The recognition and support of self-administration as treatment for HAE go back to the first international consensus document on HAE in 2003 and has been repeatedly recommended in subsequent consensus statements and guidelines $[9,15,67]$. It has been shown to be a safe and convenient option for patients, allows for early treatment, and may reduce the overall treatment costs of this group when compared to hospital-based therapy [68]. However, despite the demonstrated benefits of self-administration in terms of efficacy and improved QoL, an online survey done in the USA revealed that only $8.1 \%$ of treating physicians had patients who self-treated and only $3.5 \%$ received home healthcare assisted administration [69,70]. Although specific data in Canada is lacking, there is little reason to think it would differ much from these findings. Self-administration of blood products for rare blood disorders is not without precedent and has been the cornerstone of effective therapy for hemophilia for more than three decades in Canada [71].

Treatment is more efficacious when attacks are treated early [72]. Evidence has shown that the earlier an attack is treated the sooner it resolves [26,42,73,74]. The ability to treat an attack early depends on reducing the number of steps required between recognition of an attack that requires treatment and implementation of effective treatment. Obligating patients to travel to a health care 
facility to receive a therapy which has been shown to be effective when administered at home, or outside of a healthcare facility, adds to the delay in receiving treatment, may result in many attacks not being treated. Patients may also face difficulties in accessing treatment if local healthcare facilities are unfamiliar with this condition. The World Allergy Organization's global guideline emphasizes that all therapies should be available to all HAE patients worldwide and that home- and selfadministration are preferred because they reduce morbidity, absenteeism, cost, disease burden and potentially mortality, as well as improveQoL [15,75].

Carrying a personal supply of pdC1-INH by patients has been shown to reduce the time spent waiting for treatment [5]. Additionally, patients who selfadministered or had on-demand therapy have been shown to have reduced severity and duration of attacks, and an improved QoL.

\section{Recommendation 20 \\ All patients should be trained on self-administration of HAE-specific therapies if they are suitable candidates. If patients cannot self-administer therapy, provisions should be made to ensure timely access to all appropriate therapies. \\ Level of Evidence: Low (100\% Agree) \\ Strength of Recommendation: Strong (100\%)}

\section{Clinical considerations}

Although the level of evidence was low for the recommendation that all patients should be trained on selfadministration of HAE-specific therapies if they are suitable candidates, it was considered a strong recommendation unanimously. This is consistent with prior consensus statements and guidelines $[9,15,76]$. The importance of early therapy should not be underestimated, and barriers that affect its implementation should be removed. Currently in Canada, pdC1INH is licensed for on demand therapy (Berinert $\left.{ }^{\odot}\right)$ and for routine prophylaxis (Cinryze $\left.{ }^{\oplus}\right)$. Because pdC1INH is a blood product and dispensed by blood banks in Canada, blood banks should adapt uniform operating procedures to enable access to pdC1INH by all suitable candidates and ensure uniform care for all patients regardless of location. The Canada Health Act is intended to guarantee equal access to health services and health care. Geographic disparities in care are known to exist. Self-administration of therapy in HAE will remove these disparities. Although, pdC1INH is an intravenous product and requires special considerations including product tracking and patient training, the use of intravenous blood products for self-administration is not unique. Hemophilia self-administration programs, which are similar, have been widely implemented across Canada and have been shown to be effective $[71,77]$.
Treatments that do not require intravenous access for either acute treatment or prophylaxis would simplify selfadministered treatment. Ecallantide and icatibant are efficacious subcutaneous therapies which are administered for the treatment of acute attacks as discussed above. Ecallantide is not licensed in Canada but may be accessed through the special access program. Ecallantide should usually be administered only by a healthcare practitioner with experience and facilities to treat anaphylactic reactions which occur in 3-8\% of patients. Clinical trials are also being conducted evaluating the use of subcutaneous C1INH for LTP therapy [78,79].

Although not all patients will be suitable candidates for self-administered therapy, the option should be considered in the overall care plan of HAE patients. If patients are considered appropriate, and willing to learn self-administered therapy, they should agree to specific criteria as outlined in previously published international home-therapy guidelines $[80,81]$. With self-administered therapy, patients need to be regularly monitored to ensure appropriate control of their symptoms, compliance and competency. This is discussed further in the section on Individualized therapy.

\section{Approach to individualized therapy Background}

HAE is a dynamic chronic disease and attacks of angioedema can vary in frequency and severity over the patient's lifetime. This variability makes it important for patients to be evaluated regularly to ensure that therapy is appropriate and is being used correctly, and that side effects of therapies are being minimized. A recently published document outlines an approach to monitoring attack frequency and severity [76].

Perhaps one of the most challenging areas in patient treatment is deciding when to start or stop LTP therapy. Although guidelines exist on which agents to use when starting LTP, there is no evidence comparing the use of LTP to acute on-demand therapy regarding benefit and risk. In the absence of such evidence, given the clinical importance of this therapeutic approach, the committee attempted to determine which variables should be considered when trying to decide when to start or stop LTP.

\section{Recommendation 21}

The decision to start or stop long-term prophylaxis depends on multiple factors and should be made by the patient and an HAE specialist.

Level of Evidence: Expert Opinion (100\% Agree) Strength of Recommendation: Strong (97\% Agree, 3\% Disagree)

\section{Clinical considerations}

LTP should be considered when on-demand therapy does not allow HAE patients to lead healthy and 
productive. There was considerable discussion regarding factors that should be considered when deciding to start LTP. It was generally agreed that the key considerations in making the decision included the efficacy of ondemand therapy to control the severity and frequency of attacks. Although in the past some consensus documents have tried to define the number and severity of attacks as a reference point to consider when to start LTP [10], there was significant concern about the arbitrary nature by which this would be defined. This approach might lead to denying LTP to patients whose QoL is impacted, yet not meeting a specifically defined frequency of attacks. It was felt that, although the frequency of attacks is important, it is only one among many factors including severity of previous attacks, how readily patients can access emergency treatment, and their ability to administer on demand therapy, which should also be considered.

Although the aim of LTP is to reduce the number and severity of attacks, it does not eliminate the risk completely. Patients must be aware that starting LTP does not mean that they will no longer have attacks and that those attacks can still be fatal. All patients must have a plan to treat attacks on demand despite being on LTP therapy. All patients must be monitored to ensure that LTP is efficacious and that side effects are being recorded [76].

When starting LTP it is important to understand and emphasize that LTP is not necessarily a lifelong therapy and that treatment needs ongoing re-evaluation. It may be helpful to try to define what the expectations are as objectively as possible when starting LTP. Part of the monitoring process should be to examine these goals and ensure they are being met.

The decision to stop LTP also generated significant discussion. All participants felt LTP with androgens should be stopped immediately if a patient became pregnant, was breast feeding or if the patient was less than Tanner stage 5 development. Other factors that may lead to the consideration of stopping LTP is ongoing stable control with LTP therapy with no evidence of breakthrough attacks of angioedema. If the decision to stop LTP is made, all patients must ensure that they have access to the administration of appropriate on-demand therapy of acute attacks as is consistent with Recommendation \#20. All members of the patients comprehensive care team should be aware of the plan to stop LTP in case complications arise.

When stopping LTP with attenuated androgens or anti-fibrinolytics, the majority of participants agreed that a gradual taper is recommended, if the patient is not pregnant, while monitoring the frequency of and the impact on the patient's QoL. When stopping LTP with pdC1-INH it was felt it could either be stopped abruptly or the frequency of administration decreased, while monitoring the patient's response.
The committee was unanimous that the decision to start or stop LTP should be made jointly by the patient and an HAE specialist. The patient needs to be informed of the risks and benefits of all therapies, as discussed in the relevant sections above, to enable making an informed decision. Particular attention is needed when attenuated androgens are being considered for LTP in special populations such as women of childbearing age and children. Additionally, long-term effects on vein health need to be considered when considering repeated IV infusions.

\section{Quality of life \\ Background}

The Constitution of the World Health Organization (WHO) defines health as "A state of complete physical, mental, and social well-being not merely the absence of disease." It follows that the measurement of health and the effects of health care must include not only changes in the frequency and severity of diseases but also an estimation of wellbeing and HRQoL. The impact of HAE on a person's HRQoL can be considerable. A survey done in the USA in 2004 revealed that $85 \%$ of patients were afraid of sudden closure of their airway, $75 \%$ experienced intolerable pain and 53\% were concerned about transmitting HAE to their offspring [82]. A recent study of 457 HAE patients from the USA reported significantly poorer health-related QoL versus population norms, based on the SF-12 Physical Component Summary and Mental Component Summary [83]. Productivity was also markedly impaired in all Work Productivity and Activity Impairment-General Health categories, including 34\% overall work impairment. Because of their most recent HAE attack, workers lost a mean of 3.3 days; students lost a mean of 1.9 days. In a Swedish registry of HAE patients missed days from work and school were documented [84]. In a multicenter European Study absenteeism from work and school as well as marked loss in productivity with the most recent attack and in between attacks were recognized [85].

The Burden of Illness Study in Europe (Denmark, Germany, Spain) have shown that HAE had a high impact on daily activities during attacks and that HAE also impacted patients' daily activities between attacks $[73,85,86]$. In this study patients also reported substantial anxiety about future attacks, traveling, and passing HAE to their children [82]. Based on Hospital Anxiety and Depression Scale scores, 38 and 14\% had clinically meaningful anxiety and depression, respectively [73]. Moreover, 51\% $(\mathrm{n}=84)$ indicated that HAE had hindered their career/educational advancement [85].

In Sweden and France, attack frequency was shown to have a negative effect on HRQoL as measured by EQ5D today [84] or SF-36 [87]. Attack severity was shown to be related with absenteeism $[84,85]$. 
HAE has a significant impact on QoL both during and between attacks and on absenteeism during attacks $[73,84,85]$. In aSpanish study assessing the development of a disease-specific QoL questionnaire for adult patients with hereditary angioedema due to $\mathrm{C} 1$ inhibitor deficiency, the factors cited most often by both experts and patients as affecting their QoL included potentially lifethreatening attacks; the adverse side effects of medication (in several cases associated with chronic treatment); the unavailability of acute specific treatment at several health care centres; hereditary transmission; the lack of a known trigger which could be avoided; and the fact that it is a rare disease about which health care professionals know very little. The authors particularly noted that patients and experts may not agree on what are the most relevant aspects of HAE [88]. Aesthetics was mentioned more often by patients than by experts. On the other hand, experts were more likely to mention the adverse side effects of treatment. This finding supports the general opinion that the clinician's view of disease severity does not necessarily match with the patient's perception.

\section{Recommendation 22 \\ Health care providers should specifically address factors known to affect quality of life with HAE patients. Management of HAE should aim to improve patients' quality of life. \\ Level of Evidence: Low (100\% Agree) Strength of Recommendation: Strong (100\% Agree)}

\section{Clinical considerations}

Assessment of HAE control as it relates to the frequency, duration and severity of attacks is not the only thing to consider when monitoring patients. Data suggests that factors which relate to a patients qualify of life are important when following patients with HAE. An international specific HRQoL questionnaire for adult patients with $\mathrm{HAE}$ due to C1-inhibitor deficiency has been developed [89] and is available for its use in clinical practice. The factors that impact a patient's QoL may be different than those anticipated by the healthcare providers. Modifications should be made to improve a patient's QoL wherever possible. A small study demonstrated that self-administration of pdC1-INH improved QOL on both physical and psychological parameters. Patients were able to resume a normal life without restriction [75]. Implementation of self-administered therapy may lead to an improved QoL by reducing the suffering caused by treating attacks too late or leaving them untreated altogether. It was reinforced at the meeting by the patient representatives that there are still significant barriers to getting timely and appropriate therapy at centres across Canada, likely from the lack of awareness of $\mathrm{HAE}$ and the appropriate therapies available for treatment. On-going research is required to determine additional factors that may have impact HAE patients' QoL.

\section{Comprehensive care \\ Background}

Comprehensive care of patientsis based on integration of the organization, delivery, and management of services related to diagnosis, treatment, care, rehabilitation and health promotion. The comprehensive care model has been adopted by many rare disease groups and there is evidence in other rare diseases that this model results in better patient outcomes and reduced costs [71]. Haemophilia has used this model for decades. HAE is similar to other rare blood disorders, including haemophilia, because it is a chronic condition that is potentially life threatening and requires a highly specialized, multidisciplinary team to manage. However, although HAE is similar to other conditions, it is also different enough to require its own framework to meet the specific needs of these patients. The recommendation to provide comprehensive care for

Table 4 Requirements for comprehensive care in the management of hereditary angioedema patients

Best Clinical Treatment outcomes including:

a. A comprehensive care team made up of nurse coordinator, clinician, social worker, data manager, pain management specialist, genetic counsellor, and administrative support;

b. Access to specialized diagnostic testing;

c. Access to home treatment;

d. A networked Patient Information System to facilitate product recalls - collect data on therapy outcome measures and safety, and facilitate participation in clinical trials

e. Access to clinical advances as they become available;

f. Access to 24 hour support;

g. Access to up-to-date standards of care, including standardized wallet cards;

h. Tracking and intermittent audit of quality outcomes including beneficial and adverse outcomes through secure, comprehensive and networked data management.

Education of patients and staff regarding:

a. Responsible Self/Family Care (home care model) with home and self-infusion/administration instruction and support;

b. Developments in the cause, diagnosis, treatment, outcomes, and prognosis of HAE

c. Changes in the administrative management of the clinic

An environment conducive to research including:

a. Access to and support for clinical trials of new treatments;

b. Access to and support for translational research in diagnosis and prognosis;

c. Access to and support for psychosocial research such as quality of life studies.

An advisory or oversight board with patient group representation for each clinic

Reference [9]. 
patients with HAE is not new and exists in previously published guidelines. The specific elements of comprehensive care for HAE in Canada were published previously and are listed in Table 4.

\section{Recommendation 23 \\ Comprehensive care should be available for all patients with HAE. \\ Level of Evidence: Low (100\% Agree) \\ Strength of Recommendation: Strong (100\% Agree)}

\section{Clinical Considerations}

Although the importance of the comprehensive care model in HAE was recognized by the committee unanimously, and specific recommendations have existed with respect to its requirements, this care model is not available to all patients with HAE in Canada. The provincial and territorial model of health care funding makes implementation of nationally uniform HAE comprehensive care clinics challenging. Despite this, the fundamentals of comprehensive care should be uniform across the country and equally accessible across all geographic locations. Support should be provided by provincial and territorial governments to ensure that proper standards of care are being met. Treatments for HAE can be expensive; however inappropriate treatment of HAE may be even more costly. It was recognised by the committee that on-going monitoring of comprehensive care programs is essential to measure their impact on patients' outcomes such as disease control, QoL and economic effects.

\section{Special populations}

The committee recognized that management of HAE in certain populations were not specifically addressed in this guideline. These include paediatric HAE patients and HAE patients during lactation and menstruation. The recently published WAO document specifically addressed recommendations for the management of HAE1 and -2 in children [15]. An international consensus and practice guidelines on the gynaecologic and obstetrical management of female patients with hereditary angioedema caused by $\mathrm{C} 1$ inhibitor deficiency was recently published by Caballero et al. [90] and readers are referred to those publications with the understanding that they are not specific to Canadians.

\section{Additional files}

Additional file 1: Conflict of Interest Form.

Additional file 2: Search Strategy.

Additional file 3: Levels of Evidence and Strength of Recommendation.
Additional file 4: HAE RCT Evidence Tables. Includes data extraction, quality assessments, and study reference codes and citations for randomized control trials.

Additional file 5: HAE Lower Quality Comparison Study Evidence Tables. Includes data extraction, quality assessments, and study reference codes and citations for lower quality comparison studies.

\section{Abbreviations}

HAE: Hereditary Angioedema; C1-INH: C1 inhibitor; C1-INH-HAE: Hereditary Angioedema due to C1Inhibitor Deficiency; HRQoL: Health Related Quality of Life; HAE-1: Hereditary Angioedema Type 1; HAE-2: Hereditary Angioedema Type 2; HAE-nC1INH: Hereditary Angioedema with Normal C1 Inhibitor; F12: Factor 12; HAE-nC1INH-FXII: Hereditary Angioedema due to Factor XII mutations; HAE-nC1INH-unknown: Hereditary Angioedema due to unknown cause; QoL: Quality of Life; STP: Short-term Prophylaxis; LTP: Long-term Prophylaxis; CHAEN: Canadian Hereditary Angioedema Network; RCAH: Réseau Canadien d'angioédème héréditaire; pdC1-INH: Plasma Derived C1-inhibitor; rhC1-INH: recombinant C1-inhibitor.

\section{Competing interests}

Dr. Betschel reports personal fees from CSL, Shire, ViroPharma, Baxter, Novartis, and Canadian Blood Services unrelated to the submitted work. Ms. Badiou has no reported conflict.

Dr. Binkley reports consultation fees from Advisory Boards with Dyax, Shire, ViroPharma, and CSL Behring unrelated to the submitted work.

Dr. Hébert reports Advisory Board a consulting fee and clinical research from Shire and CSL Behring unrelated to the submitted work.

Dr. Kanani reports Advisory Boards from ViroPharma and speakers' honorarium and CME sponsorship from CSL Behring unrelated to the submitted work. Dr. Keith reports grants and personal fees from CSL Behring, personal fees from ViroPharma unrelated to the submitted work.

Dr. Lacuesta reports grants from CSL Behring, ViroPharma, and Shire; personal fees CSL Behring, ViroPharma, and Shire unrelated to the submitted work. Dr. Yang reports research grants, Advisory Board activity, unrestricted educational grants, lectures from CSL Behring and Global/National Advisory Boards, unrestricted educational grants, lectures from Shire and ViroPharma unrelated to the submitted work.

Dr. Aygören-Pürsün reports grants and personal fees from CSL Behring, Shire, ViroPharma; personal fees from Sobi; grants from BioCryst unrelated to the submitted work.

Dr. Bernstein reports grants and personal fees from CSL Behring, ViroPharma, Shire, Dyax, and Pharming/Santarus unrelated to the submitted work.

Dr. Bork reports personal fees from CSL Behring and Shire unrelated to the submitted work.

Dr. Caballero reports personal fees from Sobi, ViroPharma, Shire, Novartis, MSD, and other funding from Shire for assistance for IOS manuscripts, Dyax, and Shire for writing assistance for manuscripts unrelated to the submitted work.

Dr. Ciccardi reports personal fees from CSL Behring, ViroPharma, Shire, Dyax, Sobi, Pharming, BioCryst, Sigma Tau; and grants from ViroPharma, Shire, and Dyax unrelated to the submitted work.

Dr. Craig describes payments for lectures including service on speakers bureaus from ViroPharma, CSL Behring, Dyax, Merck, Novartis, Genentech, and Teva; consultancy with CSL Behring, Dyax, ViroPharma, Shire, and Merck; grants from ViroPharma, CSL Behring, Shire, Dyax, Pharming, Forrest, Genentech, Biota, GSK, Grifols, Novartis, Sanofi Aventis, and Boehringer Ingelheim; and payment for development of educational presentations, Vietnam Education Foundation. All unrelated to the submitted work. Dr. Farkas reports personal fees from Shire, Sobi, ViroPharma, and CSL Behring unrelated to the submitted work.

Dr. Longhurst describes grants, personal fees, and educational support from CSL Behring; personal fees and research collaboration from BioCryst; grants, personal fees, and educational support from Shire; personal fees and research collaboration from Sobi; and personal fees and research collaboration from ViroPharma unrelated to the submitted work. Dr. Zuraw reports personal fees from Shire, CSL Behring, Dyax, BioCryst, ISIS, RMEl, and WebMD unrelated to the submitted work.

Mr. Boysen reports grants from ViroPharma, Shire, Dyax, and CSL Behring unrelated to the submitted work. 
Dr. Rozita Borici-Mazi reports grants from CSL Behring; personal fees from ViroPharma and CSL Behring for Advisory Board work unrelated to the submitted work

Dr. Bowen reports Advisory Board for CSL Behring, Advisory Board and travel grants from Shire and ViroPharma unrelated to the submitted work.

Dr. Dallas reports Advisory Board funding from Shire unrelated to the submitted work.

Dr. Dean reports no conflict of interest.

Dr. Laramée reports no conflict of interest.

Dr. Leith reports no conflict of interest.

Dr. Mace reports no conflict of interest.

Dr. McCusker reports no conflict of interest.

Dr. Moote reports consulting fees from CSL Behring, ViroPharma, and Grifols unrelated to the submitted works.

Dr. Poon reports personal fees and Advisory Board activity with ViroPharma, Advisory Board activity with CSL Behring; and travel support from Shire unrelated to the submitted work.

Dr. Bruce Ritchie reports no conflict of interest.

Dr. Stark reports funding from multiple pharmaceutical industries unrelated to the submitted work.

Dr. Sussman reports consultancy fees from Shire and CSL Behring unrelated to the submitted work.

Dr. Wasserman reports personal fees from CSL Behring, Shire, and

ViroPharma unrelated to the submitted work.

\section{Authors' contributions}

SB prepared the manuscript. KLR developed the search strategy and prepared the evidence tables. All authors were involved in wording of the recommendations and reviewing and determining the level of evidence for each recommendation. All authors have read, revised and approved the manuscript.

\section{Acknowledgements}

Dr Valeria Palda and Ms Jess Rogers from the Center for Effective Practice for their part as facilitators for the development of these guidelines. Mr Peter Waite, Executive Director of CHAEN, for administrative support. Table 4, Requirements for Comprehensive Care in the Management of Hereditary Angioedema Patients, was reprinted from AACI with permission.

\section{Author details}

${ }^{1}$ University of Toronto, Toronto, Ontario, Canada. ${ }^{2}$ HAE Canada, Notre Dame des Lourdes, Manitoba, Canada. ${ }^{3}$ Department of Medicine, Laval University, Quebec City, Quebec, Canada. ${ }^{4}$ Department of Medicine, University of British Columbia, Vancouver, British Columbia, Canada. ${ }^{5}$ Department of Medicine, McMaster University, Hamilton, Ontario, Canada. ${ }^{6}$ Department of Medicine, Dalhousie University, Halifax, Nova Scotia, Canada. ${ }^{7}$ University of Ottawa Medical School, Ottawa, Ontario, Canada. ${ }^{8}$ Goethe-Universität Frankfurt am Main, Frankfurt am Main, Germany. 'Department of Internal Medicine, University of Cincinnati, Cincinnati, Ohio, USA. ${ }^{10}$ Department of Dermatology, University Hospital of the Johannes Gutenberg-University of Mainz, Mainz, Germany. ${ }^{11}$ Hospital La Paz Health Research Institute, Madrid, Spain.

${ }^{12}$ Department of Internal Medicine, Universitadeglistudi di Milano, Ospedale L. Sacco, Milan, Italy. ${ }^{13}$ Departments of Medicine and Pediatrics, Penn State University, Hershey, Pennsylvania, USA. ${ }^{14} 3$ rd Department of Internal Medicine, Faculty of Medicine, Semmelweis University, Budapest, Hungary. ${ }^{15}$ Department of Immunology, Barts and the London NHS Trust, London, England, UK. ${ }^{16}$ University of California, San Diego, San Diego, California, USA. ${ }^{17}$ HAE International, Skanderborg, Denmark. ${ }^{18}$ Department of Medicine, Queen's University, Kingston, Ontario, Canada. ${ }^{19}$ Departments of Medicine and Paediatrics, University of Calgary, Calgary, Alberta, Canada. ${ }^{20}$ Saskatoon Health Region, Saskatoon, Saskatchewan, Canada. ${ }^{21}$ BC Children's Hospital, Vancouver, British Columbia, Canada. ${ }^{22}$ Centre hospitalier de l'université de Montréal, Montréal, Quebec, Canada. ${ }^{23}$ Department of Medicine, University of Toronto, Oakville, Ontario, Canada. ${ }^{24}$ Department of Immunology, McGill University Health Centre, Montreal, Quebec, Canada. ${ }^{25}$ Department of Medicine, Western University, London, Ontario, Canada. ${ }^{26}$ Southern Alberta Rare Blood and Bleeding Disorders Comprehensive Care Program, Calgary, Alberta, Canada. ${ }^{27}$ Departments of Medicine and Medical Oncology, University of Alberta, Edmonton, Alberta, Canada.
Received: 28 August 2014 Accepted: 10 September 2014

Published: 24 October 2014

\section{References}

1. Cicardi M, Agastoni A: Hereditary Angioedema. N Engl J Med 1996, 334:1666-1667.

2. Zuraw BL: Clinical practice. Hereditary angioedema. N Engl J Med 2008, 359:1027-1036.

3. Bork K, Hardt J, Witzke G: Fatal laryngeal attacks and mortality in hereditary angioedema due to C1-INH deficiency. J Allergy Clin Immunol 2012, 130:692-697.

4. Zilberberg MD, Jacobsen T, Tillotson G: The burden of hospitalizations and emergency department visits with hereditary angioedema and angioedema in the United States 2007. Allergy Asthma Proc 2010, 31:511-519.

5. Agostoni A, Aygoren-Pursun E, Binkley KE, Blanch A, Bork K, Bouillet L: Hereditary and acquired angioedema: problems and progress: proceedings of the third $\mathrm{C} 1$ esterase inhibitor deficiency workshop and beyond. J Allergy Clin Immunol 2004, 114:S51-S131.

6. Kaplan AP, Joseph K, Silverberg M: Pathways for Bradykinin Formation and Inflammatory Disease. J Allergy Clin Immunol 2002, 109:195-209.

7. Gompels MM, Lock RJ, Morgan JE, Osborne J, Brown A, Virgo PF: A multicentre evaluation of the diagnostic efficiency of serological investigations for C1 inhibitor deficiency. J Clin Pathol 2002, 55:145-147.

8. Tarzi MD, Hickey A, Forster T, Mohammadi M, Longhurst HJ: An evaluation of tests used for the diagnosis and monitoring of $\mathrm{C} 1$ Inhibitor Deficiency: Normal serum C4 does not exclude hereditary angioedema. Clin Exp Immunol 2007, 149:513-516.

9. Bowen T, Cicardi M, Farkas H, Bork K, Longhurst HJ, Zuraw B, Aygoeren-Pürsün E, Craig T, Binkley K, Hebert J, Ritchie B, Bouillet L, Betschel S, Cogar D, Dean J, Devaraj R, Hamed A, Kamra P, Keith PK, Lacuesta G, Leith E, Lyons H, Mace S, Mako B, Neurath D, Poon MC, Rivard GE, Schellenberg R, Rowan D, Rowe A, et al: 2010 International consensus algorithm for the diagnosis, therapy and management of hereditary angioedema. Allergy Asthma Clin Immunol 2010, 6:24. doi:10.1186/1710-1492-6-24

10. Cicardi M, Bork K, Caballero T, Craig T, Li HH, Longhurst H, Reshef A, Zuraw B: HAWK (Hereditary Angioedema International Working Group). Evidencebased recommendations for the therapeutic management of angioedema owing to hereditary $\mathrm{C} 1$ inhibitor deficiency: consensus report of an International Working Group. Allergy 2012, 67:147-157.

11. Bork K: Hereditary angioedema with normal $\mathrm{C} 1$ inhibitor. Curr Allergy Asthma Rep 2009, 9:280-285.

12. Bork K: Hereditary angioedema with normal $\mathrm{C} 1$ inhibitor. Immunol Allergy Clin N Am 2013, 33:457-470.

13. Cicardi M: Classification, diagnosis, and approach to treatment for angioedema: Consensus report from the Hereditary Angioedema International Working Group. Allergy 2014, 69:602-616.

14. http://www.uspreventativeservicestaskforce.org.

15. Craig T: WAO Guideline for the Management of Hereditary Angioedema. World Allergy Organ J 2012, 5:182-199.

16. Balshem $H$, Helfand $M$, Schunemann HJ, Oxman AD, Kunz R, Brozek J: GRADE guidelines 3: Rating the quality of evidence. J Clin Epidemiol 2011, 64:401-406.

17. Andrews JC, Schunemann HJ, Oxman AD, Pottie K, Meerpohl JJ, Coello PA: GRADE guidelines: 15 . Going from evidence to recommendationdeterminants of a recommendation's direction and strength. J Clin Epidemiol 2013, 66:726-735.

18. Guyatt GH, Oxman AD, Kunz R, Falck-Ytter Y, Vist GE, Liberati A: Rating quality of evidence and strength of recommendations: Going from evidence to recommendations. BMJ 2008, 336:1049-1051.

19. Higgins JPT, Green S (Eds): Cochrane Handbook for Systematic Reviews of Interventions Version 5.1.0 [updated March 2011], The Cochrane Collaboration. 2011. Available from www.cochrane-handbook.org.

20. Cicardi M, Banerji A, Bracho F, Malbran A, Rosenkranz B, Riedl M: Icatibant, a new bradykinin-receptor antagonist, in hereditary angioedema. $N$ Engl J Med 2010, 363:532-541.

21. Cicardi M, Levy RJ, McNeil DL, Li HH, Sheffer AL, Campion M: Ecallantide for the treatment of acute attacks in hereditary angioedema. N Engl J Med 2010, 363:523-531.

22. Craig TJ, Levy RJ, Wasserman RL, Bewtra AK, Hurewitz D, Obtulowicz K. Efficacy of human $\mathrm{C} 1$ esterase inhibitor concentrate compared with 
placebo in acute hereditary angioedema attacks. J Allergy Clin Immunol 2009, 124:801-808.

23. Kunschak M, Engl W, Maritsch F, Rosen FS, Eder G, Zerlauth G: A randomized, controlled trial to study the efficacy and safety of C1-INH concentrate in treating hereditary angioedema. Transfusion 1998, 38:540-549.

24. Levy RJ, Lumry WR, McNeil DL, Li HH, Campion M, Horn PT: EDEMA4: a phase 3, double-blind study of subcutaneous ecallantide treatment for acute attacks of hereditary angioedema. Ann Allergy Asthma Immunol 2010, 104:523-529.

25. Lumry WR, Li HH, Levy RJ, Potter PC, Farkas H, Moldovan D: Randomized placebo-controlled trial of the bradykinin B2 receptor antagonist icatibant for the treatment of acute attacks of hereditary angioedema: the FAST-3 trial. Ann Allergy Asthma Immunol 2011, 107:529-537.

26. Schneider L, Lumry W, Vegh A, Williams AH, Schmalbach T: Critical role of kallikrein in hereditary angioedema pathogenesis: a clinical trial of ecallantide, a novel kallikrein inhibitor. J Allergy Clin Immunol 2007, 120:416-422.

27. Waytes AT, Rosen FS, Frank MM: Treatment of hereditary angioedema with a vapor-heated C1-INH concentrate. N Engl J Med 1996, 334:1630-1634.

28. Zuraw B, Cicardi M, Levy RJ, Nuijens JH, Relan A, Visscher S: Recombinant human $\mathrm{C} 1$-inhibitor for the treatment of acute angioedema attacks in patients with hereditary angioedema. J Allergy Clin Immunol 2010, 126:821-827.e14.

29. Zuraw BL, Busse PJ, White M, Jacobs J, Lumry W, Baker J: NanofilteredC1INH concentrate for treatment of hereditary angioedema. N Engl J Med 2010, 363:513-522.

30. Hack CE, Relan A, van Amersfoort ES, Cicardi M: Target levels of functional C1-inhibitor in hereditary angioedema. Allergy 2012, 67:123-130.

31. Donaldson VH, Rosen FS, Bing DH, Kinin: Generation in Hereditary Angioneurotic Edema (H.A.N.E.) Plasma. J Adv Exp Med Biol 1983, 156:183-191.

32. Horn PT, Li HH, Pullman WE: Hypersensitivity reactions following ecallantide treatment for acute attacks of HAE. J Allergy Clin Immunol 2010, 126:AB163.

33. Martinez-Saguer I, Rusicke E, Aygoren-Pursun E, von Hentig N, Klingebiel T, Kreuz W: Pharmacokinetic analysis of human plasma-derived pasteurized C1-inhibitor concentrate in adults and children with hereditary angioedema: a prospective study. Transfusion 2010, 50:354-360.

34. Longhurst $\mathrm{H}$ : Rhucin, a recombinant $\mathrm{C} 1$ inhibitor for the treatment of hereditary angioedema and cerebral ischemia. J Curr Opin Investig Drugs 2008, 9:310-323.

35. van Doorn MB, Burggraaf J, van Dam T, Eerenberg A, Levi M, Hack CE: A phase I study of recombinant human $\mathrm{C} 1$ inhibitor in asymptomatic patients with hereditary angioedema. J Allergy Clin Immunol 2005, 116:876-883.

36. Longhurst HJ: Emergency treatment of acute attacks in hereditary angioedema due to $\mathrm{C} 1$ inhibitor deficiency: what is the evidence? Int J Clin Pract 2005, 59:594-599.

37. Prematta M, Gibbs JG, Pratt EL, Stoughton TR, Craig TJ: Fresh frozen plasma for the treatment of hereditary angioedema. Ann Allergy Asthma Immunol 2007, 98:383-388.

38. Prematta MJ, Bewtra AK, Levy RJ, Wasserman RL, Jacobson KW, Machnig T, Craig TJ: Per-attack reporting of prodromal symptoms concurrent with C1 inhibitor treatment of hereditary angioedema attacks and. Adv Ther 2012, 10:913-922.

39. Kreuz W, Martinez-Saguer I, Aygoren-Pursun E, Rusicke E, Heller C, Klingebiel T: C1-inhibitor concentrate for individual replacement therapy in patients with severe hereditary angioedema refractory to danazol prophylaxis. Transfusion 2009, 49:1987-1995.

40. Bork K, Meng G, Staubach P, Hardt J: Treatment with C1 inhibitor concentrate in abdominal pain attacks of patients with hereditary angioedema. Transfusion 2005, 45:1774-1784.

41. Maurer M, Parish LC: The dermatology view of hereditary angio-oedema: practical diagnostic and management considerations. J Eur Acad Dermatol Venereol 2013, 27:133-141.

42. Craig TJ, Rojavin MA, Machnig T, Keinecke HO, Bernstein JA: Effect of time to treatment on response to $\mathrm{C} 1$ esterase inhibitor concentrate for hereditary angioedema attacks. Ann Allergy Asthma Immunol 2013, 111:211-215.
43. Moellman JJ, Bernstein JA, Lindsell C, Banerji A, Busse PJ, Camargo CA Jr, Collins SP, Craig TJ, Lumry WR, Nowak R, Pines JM, Raja AS, Riedl M, Ward MJ, Zuraw BL, Diercks D, Hiestand B, Campbell RL, Schneider S, Sinert R: A consensus parameter for the evaluation and management of angioedema in the emergency department. J Acad Emerg Med 2014 21:469-484.

44. Bork K: Diagnosis and treatment for hereditary angioedema with normal C1-inhibitor. Allergy Asthma Clin Immunol 2010, 6:15-23.

45. Bork K, Wulff K, Hardt J, Witzke G, Staubach P: Hereditary angioedema caused by missense mutations in the factor XII gene: clinical features, trigger factors, and therapy. J Allergy Clin Immunol 2009, 124:129-134.

46. Vitrat-Hincky V, Gompel A, Dumestre-Perard C, Boccon-Gibod I, Drouet C, Cesbron JY: Type III hereditary angio-oedema: clinical and biological features in a French cohort. Allergy 2010, 65:1331-1336.

47. Boccon-Gibod I, Bouillet L: Safety and efficacy of icatibant selfadministration for acute hereditary angioedema. Clin Exp Immunol 2012, 168:303-307.

48. Bouillet L, Ponard D, Drouet C, Jullien D, Massot C: Angioedema and oral contraception. Dermatology 2003, 206:106-109.

49. Bork K, Hardt J, Staubach-Renz P, Witzke G: Risk of laryngeal edema and facial swellings after tooth extraction in patients with hereditary angioedema with and without prophylaxis with C1 inhibitor concentrate: a retrospective study. Oral Surg Oral Med Oral Pathol Oral Radiol Endod 2011, 112:58-64

50. Farkas H, Gyeney L, Gidofalvy E, Fust G, Varga L: The efficacy of short-term danazol prophylaxis in hereditary angioedema patients undergoing maxillofacial and dental procedures. J Oral Maxillofac Surg 1999, 57:404-408.

51. Jurado-Palomo J, Munoz-Caro JM, Lopez-Serrano MC, Prior N, Cabanas R, Pedrosa M: Management of dental-oral procedures in patients with hereditary angioedema due to $\mathrm{C} 1$ inhibitor deficiency. J Investig Allergy Clin Immunol 2013, 23:1-6.

52. Farkas H, Zotter Z, Csuka D, Szabo E, Nebenfuhrer Z, Temesszentandrasi G: Short-term prophylaxis in hereditary angioedema due to deficiency of the C1-inhibitor-a long-term survey. Allergy 2012, 67:1586-1593

53. Aygören-Pürsün E, Martinez Saguer I, Kreuz W, Klingebiel T, Schwabe D: Risk of angioedema following invasive or surgical procedures in HAE type I and II-the natural history. Allergy 2013, 68:1034-1039.

54. Maya K, Nanda M, Singh U, Wilmot J, Bernstein J: A cross-sectional questionnaire assessing patient and physician use of short-term prophylaxis for hereditary angioedema. Ann Allergy Asthma Immunol 2014, 113:198-203.

55. Gelfand JA, Sherins RJ, Alling DW, Frank MM: Treatment of hereditary angioedema with danazol.Reversal of clinical and biochemical abnormalities. N Engl J Med 1976, 23(295):1444-1448.

56. Hosea SW, Santaella ML, Brown EJ, Berger M, Katusha K, Frank MM: Long-term therapy of hereditary angioedema with danazol. Ann Intern Med 1980, 93:809-812.

57. Sheffer AL, Fearon DT, Austen KF: Clinical and biochemical effects of stanozolol therapy for hereditary angioedema. J Allergy Clin Immuno 1981, 68:181-187.

58. Cicardi M, Bergamaschini L, Cugno M, Hack E, Agostoni G, Agostoni A: Long-term treatment of hereditary angioedema with attenuated androgens: a survey of a 13-year experience. J Allergy Clin Immunol 1991, 87:768-773

59. Bork K, Bygum A, Hardt J: Benefits and risks of danazol in hereditary angioedema: a long-term survey of 118 patients. Ann Allergy Asthma Immunol 2008, 100:153-161.

60. Fust $G$, Farkas $H$, Csuka D, Varga L, Bork K: Long-term efficacy of danazol treatment in hereditary angioedema. Eur J Clin Invest 2011, 41:256-262.

61. Cicardi M, Castelli R, Zingale LC, Agostoni A: Side effects of long-term prophylaxis with attenuated androgens in hereditary angioedema: comparison of treated and untreated patients. J Allergy Clin Immunol 1997, 99:194-196.

62. Farkas H, Czaller I, Csuka D, Vas A, Valentin S, Varga L: The effect of long-term danazol prophylaxis on liver function in hereditary angioedema-a longitudinal study. Eur J Clin Pharmacol 2010, 66:419-426.

63. Gandhi PK, Gentry WM, Bottorff MB: Thrombotic events associated with C1 esterase inhibitor products in patients with hereditary angioedema: investigation from the United States Food and Drug Administration 
adverse event reporting system database. Pharmacotherapy 2012, 32:902-909.

64. Kalaria S, Craig T: Assessment of hereditary angioedema treatment risks. Allergy Asthma Proc 2013, 34:519-522.

65. Sheffer AL, Austen KF, Rosen FS: Tranexamic acid therapy in hereditary angioneurotic edema. N Engl J Med 1972, 287:452-454.

66. Gwynn CM: Therapy in hereditary angioneurotico edema. Arch Dis Child 1974, 49:636-640.

67. Bowen T, Cicardi M, Farkas H, Bork K, Kreuz W, Zingale L, Varga L, Martinez-Saguer I, Aygören-Pürsün E, Binkley K, Zuraw B, Davis A 3rd, Hebert J, Ritchie B, Burnham J, Castaldo A, Menendez A, Nagy I, Harmat G, Bucher C, Lacuesta G, Issekutz A, Warrington R, Yang W, Dean J, Kanani A, Stark D, McCusker C, Wagner E, Rivard GE, et al: Canadian 2003 International Consensus Algorithm For the Diagnosis, Therapy, and Management of Hereditary Angioedema. J Allergy Clin Immunol 2004, 114:629-637.

68. Blasco AJ, Lázaro P, Caballero T, Guilarte M: Social costs of icatibant selfadministration vs. health professional-administration in the treatment of hereditary angioedema in Spain. Health Econ Rev 2013, 3:2. doi:10.1186/2191-1991-3-2.

69. Riedl M: Hereditary angioedema therapies in the United States: movement toward an international treatment consensus. J Clin Ther 2012, 34:623-630.

70. Craig TJ: Recent advances in hereditary angioedema self-administration treatment: summary of an International Hereditary Angioedema Expert Meeting. Int Arch Allergy Immunol 2013, 161:26-27.

71. Teitel JM, Barnard D, Israels S, Lillicrap D, Poon MC, Sek J: Home management of haemophilia. J Hemophilia 2004, 10:118-133.

72. Tourangeau LM, Castaldo AJ, Davis DK, Koziol J, Christiansen SC, Zuraw BL: Safety and efficacy of physician-supervised self-managed $\mathrm{C} 1$ inhibitor replacement therapy. Int Arch Allergy Immunol 2012, 157:417-424.

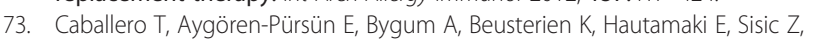
Wait S, Boysen HB: The humanistic burden of hereditary angioedema: results from the Burden of Illness Study in Europe. Allergy Asthma Proc 2014, 35:47-53.

74. Maurer M, Aberer W, Bouillet L, Caballero T, Fabien V: Hereditary Angioedema Attacks Resolve Faster and Are Shorter after Early Icatibant Treatment. PLoS One 2013, 8:e53773.

75. Bygum A, Andersen KE, Mikkelsen CS: Self-administration of intravenous C1-inhibitor therapy for hereditary angioedema and associated quality of life benefits. Eur J Dermatol 2009, 19:147-151.

76. Zuraw BL, Banerji A, Bernstein JA, Busse PJ, Christiansen SC, Davis-Lorton M, Frank MM, Li HH, Lumry WR, Riedl M: US Hereditary Angioedema Association Medical Advisory Board 2013 recommendations for the management of hereditary angioedema due to C1 inhibitor deficiency. J Allergy Clin Immunol In Prac 2013, 1:458-467

77. Soucie JM, Symons J, Evatt B, Brettler D, Huszti H, Linden J: Home-based factor infusion therapy and hospitalization for bleeding complications among males with hemophilia. J Hemophilia 2001, 7:198-206.

78. http://clinicaltrials.gov/show/NCT01912456.

79. http://clinicaltrials.gov/show/NCT01095497

80. Longhurst HJ, Farkas H, Craig T, Aygören-Pürsün E, Bethune C, Bjorkander J, Bork K, Bouillet L, Boysen H, Bygum A, Caballero T, Cicardi M, Dempster J, Gompels M, Gooi J, Grigoriadou S, Huffer U, Kreuz W, Levi MM, Long J, Martinez-Saguer I, Raguet M, Reshef A, Bowen T, Zuraw B: HAE international home therapy consensus document. Allergy, Asthma Clin Immunol 2010, 6:22.

81. Cicardi M, Craig TJ, Martinez-Saguer I, Hebert J, Longhurst HJ: Review of recent guidelines and consensus statements on hereditary angioedema therapy with focus on self-administration. Int Arch Allergy Immunol 2013, 161:3-9.

82. Huang SW: Results of an on-line survey of patients with hereditary angioedema. Allergy Asthma Proc 2004, 25:127-131.

83. Lumry WR, Castaldo AJ, Bernon MK, Blaustein MB, Wilson DA, Horn PT: The humanistic burden of hereditary angioedema: impact on health-related quality of life, productivity, and depression. Allergy Asthma Proc 2010, 5:407-414.

84. Nordenfelt P, Dawson S, Wahlgren CF, Lindfors A, Mallbris L, Björkander J: Quantifying the burden of disease and perceived health state in patients with hereditary angioedema in Sweden. Allergy Asthma Proc 2014, 35:185-190.

85. Aygören-Pürsün E, Bygum A, Beusterien K, Hautamaki E, Sisic Z, Wait S, Boysen HB, Caballero T: Socioeconomic burden of hereditary angioedema: results from the hereditary angioedema burden of illness study in Europe. J Orphanet J Rare Dis 2014, 99:99-105.

86. Bygum A, Aygören-Pürsün E, Caballero T, Beusterien K, Gholizadeh S, Musingarimi $\mathrm{P}$, Wait $\mathrm{S}$, Boysen $\mathrm{H}$ : The hereditary angioedema burden of illness study in Europe (HAE-BOIS-Europe): background and methodology. BMC Dermatol 2012, 12:4. doi:10.1186/1471-5945-12-4.

87. Bouillet L, Launay D, Fain O, Boccon-Gibod I, Laurent J, Martin L, Montauban V, Finck K, Bouée S, Gompel A, Kanny G: French National Reference Center for Hereditary Angioedema (CREAK). Hereditary angioedema with C1 inhibitor deficiency: clinical presentation and quality of life of 193 French patients. J Ann Allergy Asthma Immunol 2013, 111:290-294.

88. Prior N, Remor E, Gomez-Traseira C, Lopez-Serrano C, Cabanas R, Contreras $\mathrm{J}$ : Development of a disease-specific quality of life questionnaire for adult patients with hereditary angioedema due to $\mathrm{C} 1$ inhibitor deficiency (HAE-QoL): Spanish multi-centre research project. Health Qual Life Outcomes 2012, 10:82.

89. Prior N, Remor E, Pérez-Fernández E, Gómez-Traseira C, Caminoa MJ, Gayá F, Aberer W, Barrera OM, Betschel SD, Bouillet L, Bygum A, Farkas H, Grumach A, Grivcheva-Panovska V, Levi M, Longhurst H, Malbran A, Moldovan D, Porebski G, Reshef A, Staubach P, Zanichelli A, Zhi YX, Caballero T: IHAE-Qol: Specific Health-Related Quality Of Life (HRQoL) Questionnaire In Hereditary Angioedema Due To C1 Inhibitor Deficiency (HAE-C1INH). J Allergy Clin Immunol 2014, 133:AB33. POSTER.

90. Caballero T, Farkas H, Bouillet L, Bowen T, Gompel A, Fagerberg C, Bjökander J, Bork K, Bygum A, Cicardi M, de Carolis C, Frank M, Gooi JH, Longhurst H, Martínez-Saguer I, Nielsen EW, Obtulowitz K, Perricone R, Prior N, C-1-INH Deficiency Working Group: International consensus and practical guidelines on the gynecologic and obstetric management of female patients with hereditary angioedema caused by $\mathrm{C} 1$ inhibitor deficiency. J Allergy Clin Immunol 2012, 129:308-320.

doi:10.1186/1710-1492-10-50

Cite this article as: Betschel et al:: Canadian hereditary angioedema guideline. Allergy, Asthma \& Clinical Immunology 2014 10:50.

\section{Submit your next manuscript to BioMed Central and take full advantage of:}

- Convenient online submission

- Thorough peer review

- No space constraints or color figure charges

- Immediate publication on acceptance

- Inclusion in PubMed, CAS, Scopus and Google Scholar

- Research which is freely available for redistribution 